\title{
Cryopreservation of Cold-tender Apple Germplasm
}

\author{
Manfredo J. Seufferheld and Cecil Stushnoff \\ Department of Horticulture and Landscape Architecture, Colorado State University, Fort Collins, \\ CO 80523 \\ Philip L. Forsline \\ U.S. Department of Agriculture National Germplasm Repository for Apple and Grape, Plant Genetic \\ Resources Unit, Geneva, NY 14456-0462
}

\author{
Gerardo H. Terrazas Gonzalez \\ Department of Statistics, Colorado State University, Fort Collins, CO 80523
}

\begin{abstract}
ADIfIOA- alginate encapsulation, dehydration, freeze-desiccation, sucrose, raffinose, Malus sylvestris var. domestica

Abstract. Unlike cold-hardy apple germplasm, dormant vegetative buds from cold-tender accessions require stabilization of meristematic tissue to protect against injury during desiccation and cryopreservation. Dormant buds of six apple cultivars [Malus sylvestris (L.) Mill. var. domestica (Borkh.) Mansf. 'Cox's Orange Pippin', 'Einshemer', 'Golden Delicious', 'Jonagold', 'K-14', and 'Mutsu'] collected at specific intervals in 1993, 1994, and 1995 at Geneva, N.Y., were stabilized by encapsulation in $5 \%$ alginate, treated with step-wise imbibition of 0.5 to 1.0 sucrose and 0.2 raffinose solution, and desiccated with forced air at $0^{\circ} \mathrm{C}$. Sugar-alginate stabilization reduced injury during desiccation, increased cold-hardiness of the six cold-tender cultivars frozen to $-30^{\circ} \mathrm{C}$, and improved recovery following cryopreservation of buds collected before optimal cold acclimation was attained. Sucrose tissue levels did not increase following stabilization treatment, but levels of glucose and fructose, and of an unknown disaccharide increased. This procedure used nontoxic cryoprotectants, and has potential to expand the scope of dormant bud cryopreservation to include cold-tender apple germplasm.
\end{abstract}

Dormant vegetative buds of apple (Malus sylvestris var. domestica ) and stone fruits have been successfully cryopreserved using controlled drying and freezing protocols (Stushnoff, 1991; Tyler and Stushnoff, 1988 a, 1988b). This technique is simple, reproducible, and requires relatively nonelaborate facilities. There are, however, some limitations in the broad application of this technology. Buds must be collected during dormancy and in the acclimated state. Although dormant bud cryopreservation is applicable to a large number of cold hardy taxa, cold-tender genotypes require special manipulation to maximize cold hardiness and to stabilize tissues against desiccation injury in order to survive exposure to liquid nitrogen temperatures. Some apple germplasm, especially very cold-tender taxa, survive poorly even at maximum cold hardiness (Forsline et al., 1998).

Understanding mechanisms controlling desiccation tolerance aids manipulation of cold-tender apple taxa that are susceptible to injury during water loss (Vertucci and Stushnoff, 1992). Increased carbohydrate levels are often associated with cold hardiness. In apple, Pochrinot (1983) and Sakai and Larcher (1987) found a positive correlation between sugar content and freezing tolerance. Endogenous raffinose family oligosaccharide levels are strongly associated with dormancy and cold hardiness in many cold hardy species Bachmann et al., (1994) and Stushnoff et al., (1994). Compatible osmolytes, primarily soluble sugars and polyols, can serve as osmoregulators (Alscher and Cumming, 1990). They can also depress the equilibrium freezing point, and are known to favor supercooling and glass formation (Burke, 1987). Other proposed beneficial roles during periods of abiotic stress are oxygen free-radical scavenging (Benson et al., 1992;

Received for publication 31 Aug. 1998. Accepted for publication 6 Aug. 1999. Support from U.S. Department of Agriculture-National Seed Storage Laboratory, Fort Collins, Colo., and the Colorado Agricultural Experiment Station, project number 6901 , is gratefully acknowledged. The cost of publishing this paper was defrayed in part by the payment of page charges. Under postal regulations, this paper therefore must be hereby marked advertisement solely to indicate this fact.
Purvis, 1993; Smirnoff and Cumbes, 1989), prevention of sucrose crystallization under desiccating conditions (Koster, 1991; Leopold and Vertucci, 1986), and stabilization of photosynthetic membranes during freezing stresses (Hincha and Smith, 1990; Steponkus, 1984). A few specific amino acids, such as proline and glycine betaine are also known to increase in plant tissues exposed to environmental stresses (Guy, 1990), but their use as exogenous plant cryoprotectants has not been particularly effective.

Differential scanning calorimetry of cold hardy species has shown that dormant vegetative bud tissues undergo transitions to a glassy amorphous state at liquid nitrogen temperatures (Stushnoff et al., 1988). Sugars are good glass formers, especially monosaccharides, disaccharides, and lower molecular weight oligosaccharides (Slade and Levine, 1990;1995). Evidence from biophysical and biochemical research on cold acclimation, cryobiology, and desiccation tolerance suggests that one role of sugars during dehydration may be to replace vital water molecules from cellular macromolecules, avoiding denaturation (Carpenter et al., 1990). Sucrose can stabilize lysozyme against desiccation injury during lyophilization (Carpenter et al., 1993; Remmele et al., 1994, 1997). Sugars can also interact with phospholipids reducing Van der Waals interactions among hydrocarbon chains, thus maintaining the liquid crystalline structure of the membrane (Crowe et al., 1984, 1988, 1990). Leborgne et al. (1995) increased freezing resistance of Eucalyptus gunnii Hook. cells at $-18{ }^{\circ} \mathrm{C}$ by treating with fructose and raffinose.

The primary objective of this research was to test the hypothesis that a sugar-alginate treatment could be used to stabilize coldtender vegetative buds of apple during desiccation and cryopreservation. Specific goals were to 1) examine a sugaralginate stabilization protocol with several cold-tender cultivars; 2 ) determine survival over a range of moisture levels; 3 ) determine if treatment could enhance cold hardiness of cold-tender cultivars sufficiently to optimize survival during cryopreservation; 
4) evaluate the effectiveness of tissue browning as an indicator of cryopreservation injury and 5) determine treatment response at several collection dates. A secondary objective was to examine changes in soluble carbohydrate levels as a consequence of the stabilization treatments.

\section{Materials and Methods}

Planf-Materiat-ANĐ-Hangling- Dormant vegetative buds from current season's growth of six apple cultivars ('Mutsu', 'Golden Delicious', 'Cox's Orange Pippin', 'Einshemer', 'Anna', and 'K-14' rootstock) were shipped with a cold pack in an insulated container by overnight air express from the U.S. Department of Agriculture National Germplasm Repository for Apple and Grape, Plant Genetic Resources Unit, Geneva, N.Y., to Fort Collins, Colo., each month from September to January during 1993, 1994, and 1995. 'Mutsu' was selected as a control because of consistently good survival by conventional dormant bud cryopreservation procedures, compared to 'Golden Delicious', which has been decidedly inconsistent (Forsline et al., 1998). 'Cox's Orange Pippin', 'Einshemer', 'Jonagold', and buds from 'K-14' rootstock are considered cold-tender, because in preliminary tests these cultivars produced low survival following conventional dormant bud cryopreservation. Choice of cultivars for each experiment was based upon availability of material and past history of response to cryopreservation. Thus, while not all cultivars were used in each experiment, it was considered essential to sample several different cultivars to determine general applicability of the treatments used. All samples were sealed in 6 $\mathrm{mm}$ thick polyethylene bags to prevent moisture loss, and stored at $-4{ }^{\circ} \mathrm{C}$ until used. Experiments were conducted as soon as feasible (1 to 6 weeks) after delivery.

Sugar=Alginate-STABHzation-TREATMENT- Dormant apple shoots were cut into ${ }_{\{\text {Xapprox } x \mid} 2.5 \mathrm{~cm}$ long sections, each with one bud. Buds were encapsulated in 5\% medium viscosity alginic acid and 0.5 sucrose. After encapsulation, the buds were imbibed for 24 $\mathrm{h}$ at $0{ }^{\circ} \mathrm{C}$ in a solution containing both $0.5 \mathrm{H}$ sucrose and $100 \mathrm{mH}$ $\mathrm{CaCl}_{2}$ to cross-link the alginic acid solution into a stable gel. This was followed by a stepwise stabilization treatment at $0{ }^{\circ} \mathrm{C}$, consisting of $24 \mathrm{~h}$ in $0.7 \mathrm{~m}$ sucrose, followed by $24 \mathrm{~h}$ in a solution containing $1.0 \mathrm{~m}$ sucrose and $0.2 \mathrm{~m}$ raffinose. Sugars were excluded from all steps in the alginate and control treatments in an experiment designed to test the effect of alginate encapsulation with and without sugar imbibition.

Đesiccation-tolerance- Moisture levels of bud samples (three replications of 10 buds) were reduced by exposing nontreated control buds and alginate encapsulated and imbibed buds to low humidity $(10 \%$ to $15 \%$ ) in an environmental chamber at 0 ${ }^{\circ} \mathrm{C} \pm 2{ }^{\circ} \mathrm{C}$ to achieve a moisture content ranging from $12 \%$ to $40 \%$ (fresh weight basis). A companion set (five replications of three buds) was used to monitor progressive water loss, as needed for indicator samples. Moisture content of the buds was determined gravimetrically after drying at 70 to $75{ }^{\circ} \mathrm{C}$ for 5 days in a convection oven. Change in sensitivity to desiccation following drying to various moisture levels was evaluated by cutting the buds transversely and visually observing oxidative browning in the tissues. Before anatomical evaluation, buds were incubated in moist peatmoss with the alginate capsule removed at room temperature $\left(23 \pm 3^{\circ} \mathrm{C}\right)$ for $7 \mathrm{~d}$ to allow oxidative browning to occur in damaged tissues.

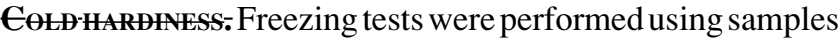
collected at the beginning of each month in October, November, and January 1994-95 to detect changes in freezing resistance of cold-tender buds subjected to sugar-alginate stabilization, compared to nontreated controls. Freezing tests to determine cold hardiness were conducted as soon as the samples were received. Samples from three cultivars, 'Mutsu', 'Jonagold' and 'K-14' were placed between moist paper towels in $4 \mathrm{~mm}$ thick, sealed poly bags and frozen in a Tenny Junior programmable freezer (Tenny Inc., South Brunswick, N.J.) by lowering the temperature at $5^{\circ} \mathrm{C} \cdot \mathrm{h}^{-1}$ from 0 to -20 and $-30^{\circ} \mathrm{C}$. Test temperatures were held for $1 \mathrm{~h}$ to permit attaining uniform target temperatures for all samples. Once each target temperature was achieved, three replications of 10 buds per test temperature, were removed from the freezer and incubated in moist peatmoss at $\left(21 \pm 3{ }^{\circ} \mathrm{C}\right)$ for $7 \mathrm{~d}$ before visual observation of tissue browning.

Eryopreservation-Sugar-alginate treated buds and controls, dehydrated to various moisture levels, were placed in plastic tubes resistant to liquid nitrogen and cryopreserved by slow cooling $\left(2{ }^{\circ} \mathrm{C} \cdot \mathrm{h}^{-1}\right.$ to $-30^{\circ} \mathrm{C}$, held $24 \mathrm{~h}$ at $\left.-30{ }^{\circ} \mathrm{C}\right)$ followed by immersion in the liquid phase $\left(-196^{\circ} \mathrm{C}\right)$ of liquid nitrogen (LN). Buds were exposed at least $24 \mathrm{~h}$ to $\mathrm{LN}$, thawed and incubated in moist peatmoss at $\left(23 \pm 3{ }^{\circ} \mathrm{C}\right)$ for $10 \mathrm{~d}$ before evaluation of injury. The extent of injury after cryopreservation was evaluated by two methods. Tissue browning was evaluated using the following numeric rating scale: $0=$ no injury; $1=$ dull green; $2=$ brown connecting bud vascular tissue; 3 = brown cortical tissue and/or bud; $4=$ all tissues brown. Samples scored 0 were considered uninjured and all other scores were considered as nonsurvivors when percentage survival data were calculated. Cryopreserved buds were also evaluated independently at the U.S. Department of Agriculture National Apple Clonal Repository, Geneva, N.Y. Following treatment and cryopreservation at Colorado State University, buds were removed from liquid nitrogen and shipped by overnight air express to the National Clonal Apple Repository, Geneva, N.Y. for bud grafting. Buds were rehydrated in moist peatmoss at $+2{ }^{\circ} \mathrm{C}$ for 10 to $14 \mathrm{~d}$ and patch budded to greenhouse-grown rootstocks. Since budding requires both viable bud and cortical tissue, survival values reflect the percentage of samples with no injury to either bud or cortical tissue. Results from both evaluation methods were correlated to examine agreement.

Soluble-sugars. Sugar content was measured in cortical tissues after the sugar-alginate stabilization treatment, and in control samples. The epidermal bark layer, but not the cortical tissues, and $0.5 \mathrm{~cm}$ from both cut-ends of the twigs were discarded to minimize measurement of the imbibing solution and to more closely reflect tissue sugar content in the vicinity of the bud itself. Tissues were frozen in LN, lyophilized, ground in a Wiley Mill (Thomas Scientific, Philadelphia, Pa.), screened with a CSC Scientific Sieve Shaker (Westchester, Pa.) through a 100 mesh sieve (150- $\mu \mathrm{m}$ opening), and derivatized directly by trimethysilation for analysis by gas chromatography (Sweeley et al., 1963). Preliminary tests using hot water and methanol extraction showed no increases in yield of soluble sugars over direct derivatization when a finely ground and screened powder preparation was used. Sugar levels were determined from a ratio of known peak areas to methyl-alpha-D-glucopyranoside as an internal standard.

Unknown peaks were identified qualitatively by their retention times and normalized quantitatively by comparison with the area of the internal standard. Samples were analyzed for sugar content using a Hewlett Packard 5890 series II, (Hewlett Packard, Inc., Avondale, Pa.) gas chromatograph equipped with a split- 


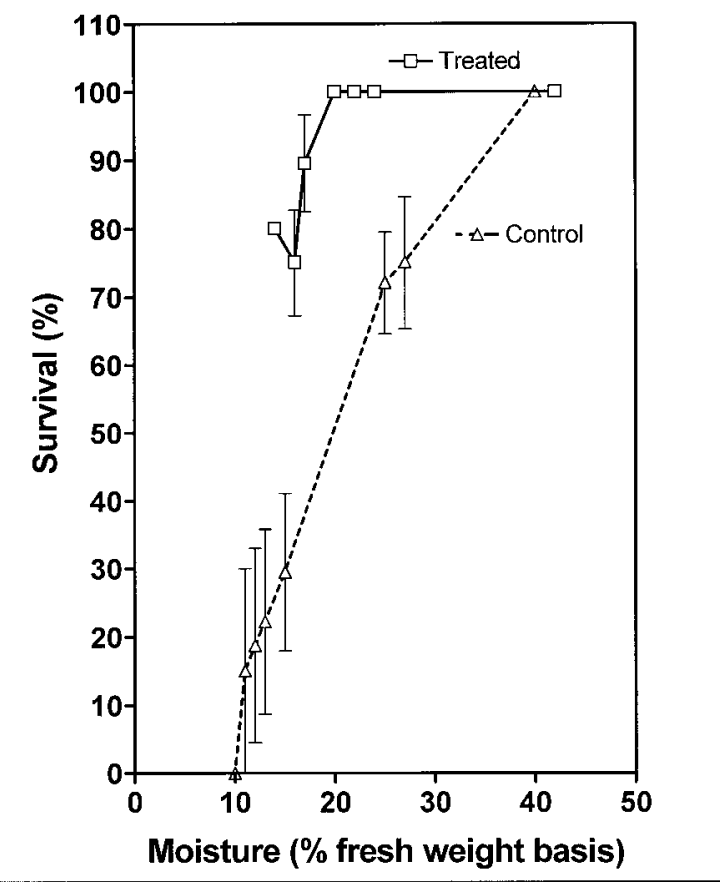

splitless injector, FID detector, and a DB-1 fused silica (crosslinked and surface bonded dimethyl-polysiloxane) 30-m (xtimesx 0.25-mm-diameter microcapillary column, manufactured by (J\&W Scientific, Folsom, Calif.). Grade 5 (99.999\%) purity helium $(\mathrm{He})$ was used as the carrier gas and hexane as the injection solvent. The injection temperature was $325{ }^{\circ} \mathrm{C}$ and the oven heating program was as follows: $180{ }^{\circ} \mathrm{C}$ for $2 \mathrm{~min}$; ramp 1 at 6 ${ }^{\circ} \mathrm{C} \cdot \mathrm{min}^{-1}$ to $\mathrm{ramp} 2,40 / \mathrm{min}$ to $325{ }^{\circ} \mathrm{C}$ and hold for $20 \mathrm{~min}$. Detector temperature was $350{ }^{\circ} \mathrm{C}$.

Statistical analysis was calculated at $P$ (xtequalx) 0.05 using SAS Inst. Inc., Cary, N.C., release 6.03 computer software. Analysis of variance for a completely randomized design, was applied to determine the significance of treatment means. Analyses of data were performed on arc sine transformed percentages. This procedure caused a saturated model in the freezing test and cryopreservation analyses resulting in no degrees of freedom in the error term. Thus, the strategy employed was first to include all possible effects in a preliminary model for the freezing test and LN survival, then those that were nonsignificant were included in the error term (Montgomery, 1984 ). The effect of moisture content on LN survival was analyzed as a covariant. Significance of imbibition on cortical tissue sugar level was analyzed with an unpaired Student's $t$ test to compare controls to treated samples for each sugar, for each sample month.

\section{Results and Discussion}

Đesfecation-quefanee- Unlike cold-tender apple buds, those that are cold hardy tolerate low moisture content when fully cold acclimated (Tyler and Stushnoff 1988a). The cold-tender cultivars tested in this study were injured when subjected to dehydration (Fig. 1). Viability decreased as moisture levels in the control buds were reduced below $40 \%$, but when buds from the same

Table 1. Analysis of variance (ANOVA) for cold hardiness at $-20^{\circ} \mathrm{C}$ and $-30{ }^{\circ} \mathrm{C}$ of 'Jonagold', 'K-14', and 'Mutsu' collected in October, November, and January, and treated with sugar-alginate encapsulation $($ model MSE $=0.0367, \mathrm{df}=12$ ).

\begin{tabular}{lccr}
\hline \hline Source & df & F value & $P$ value \\
\hline Month $(\mathrm{M})$ & 2 & 16.02 & 0.0004 \\
Temp $(\mathrm{T})$ & 1 & 93.09 & 0.0001
\end{tabular}

Fig. 1. Survival of dormant vegetative apple buds collected 15 Jan. 1993, from four, cold-tender cultivars subjected to dehydration conditions $(10 \%$ to $15 \%$ relative humidity at $\left({ }^{\circ} \mathrm{C}\right)$. Sugar-alginate buds were handled as described in materials and methods. Vertical bars represent sE for 15 buds from each of 'Cox's Orange Pippin', 'Einshemer', 'Golden Delicious' and 'K-14' rootstock.

cultivars were subjected to the sugar-alginate stabilization treatment, they maintained high viability, even at moisture levels of $15 \%$ to $20 \%$. Treated samples could not be dried lower than $15 \%$ with the low humidity, cold temperature drying method employed. Sugar-alginate stabilization of cold-tender germplasm thus overcame the first critical stage of potential injury during cryopreservation by reducing injury during water loss.

EOLO-HARDINEss: There were significant interactions between collection month and freeze test temperatures, and between freeze-test temperature and sugar-alginate stabilization treatment (Fig. 1, Table 1). There was no significant difference in cold hardiness among cold-tender cultivars (Table 1). Survival of control samples averaged $91 \%$ at $-20{ }^{\circ} \mathrm{C}$, but only $28 \%$ at $-30{ }^{\circ} \mathrm{C}$. Regardless of the collection date, survival of treated samples averaged $98 \%$ at $-20{ }^{\circ} \mathrm{C}$ and $77 \%$ at $-30{ }^{\circ} \mathrm{C}$. Sugar-alginate stabilization treatments had a significant effect on survival at -30 ${ }^{\circ} \mathrm{C}$. Highest survival at $-30{ }^{\circ} \mathrm{C}$ occurred in November and the lowest in January, suggesting the January samples had satisfied their dormancy requirement and had already begun to deharden under conditions experienced at Geneva, N.Y., in 1994-95. Cryopreservation of dormant apple buds with cold hardy cultivars was found to be most effective when a slow freeze step with exposure to $-30{ }^{\circ} \mathrm{C}$ was included in the protocol (Tyler and Stushnoff, 1988b). If a similar $-30^{\circ} \mathrm{C}$ is to be used with cold tender cultivars, sugar-alginate stabilization must be added to maximize cold hardiness or the buds will be killed long before they are exposed to liquid nitrogen temperatures.

Eryopreservation: The critical dependance on low moisture levels for survival in liquid nitrogen is illustrated in Fig. 3. These data are pooled for three cultivars ('Mutsu', 'K-14', 'Jonagold') collected in 1994 for September, October, and November and in 1995 for January. While these pooled data show considerable scatter in the data points, several points are evident. Survival was poor for nontreated samples $(0 \%$ to $40 \%)$, diminishing linearly $\left(R^{2}=0.32, P_{\{\text {XItcqual }\}} 0.01\right)$ as moisture content decreased. In contrast, stabilized bud survival averaged $62 \%$ for moisture content ranging from $12 \%$ to $26 \%$ and there was no significant relationship between moisture content and survival in liquid nitrogen. Analysis of covariance showed no effect of moisture content on survival of buds in $\mathrm{LN}$ as a covariate, thus the treatment largely removes moisture content as a yariable control- 

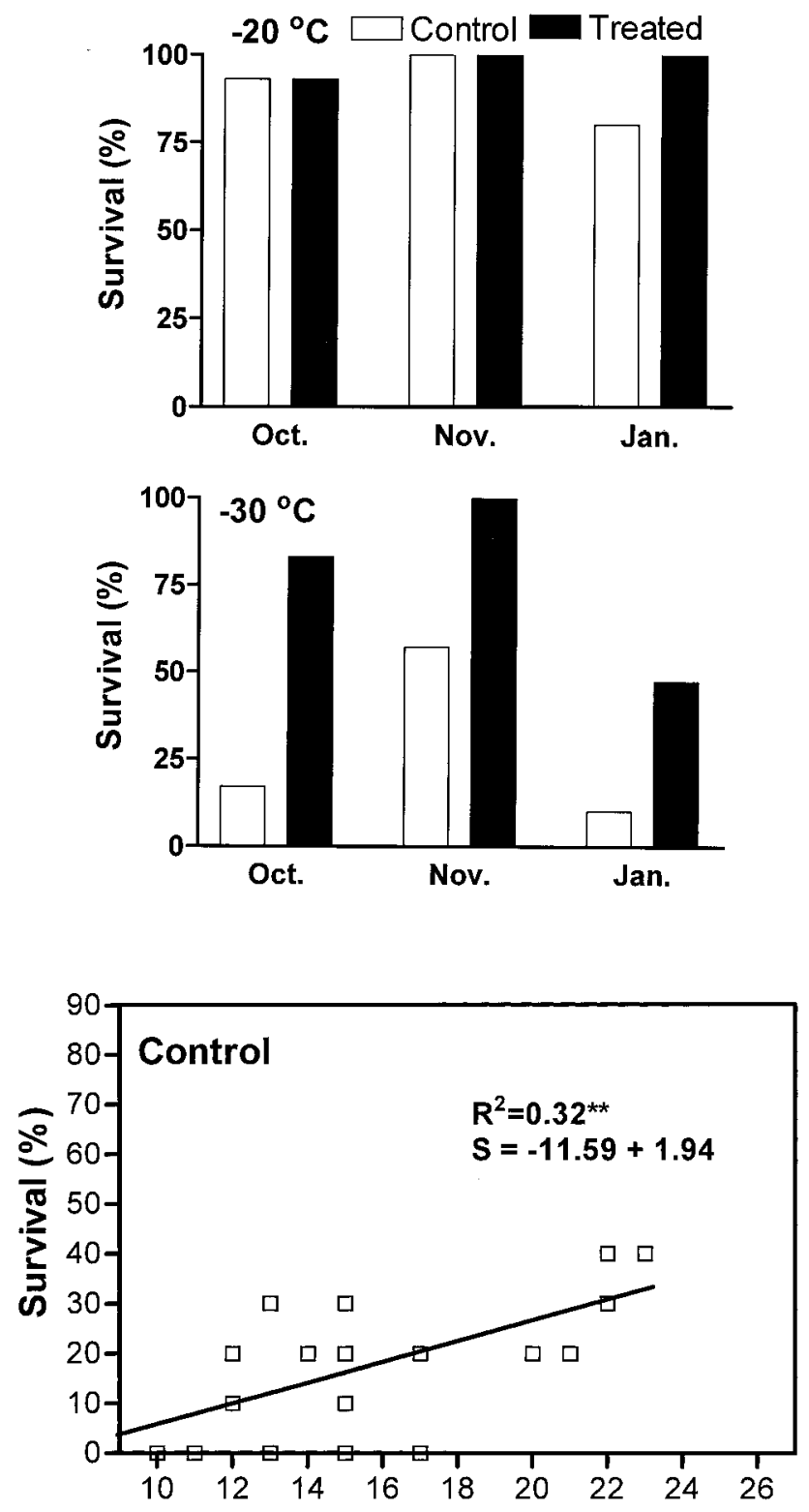

Moisture content ( $\%$ fresh weight basis)

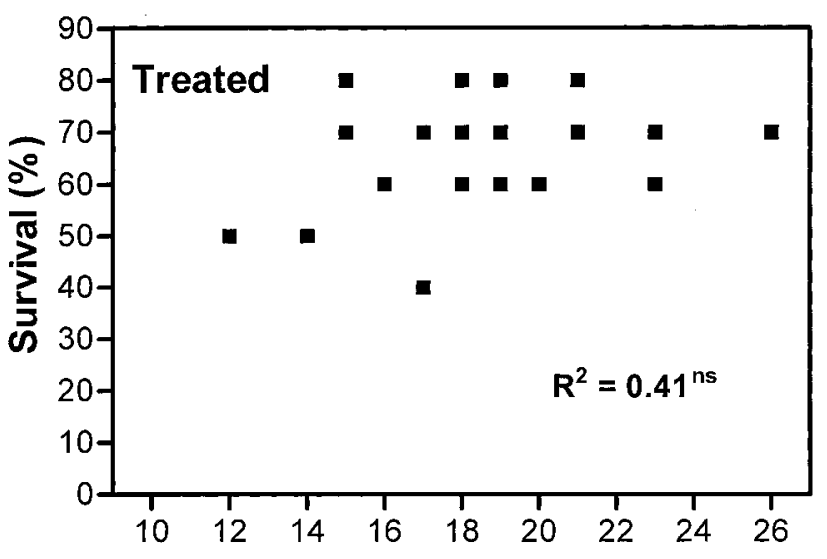

Moisture content (\% fresh weight basis)
Fig. 2. Effect of sugar-alginate stabilization treatment on cold hardiness of dormant vegetative buds of 'Jonagold', 'K-14' and 'Mutsu' following a freeze test at $5{ }^{\circ} \mathrm{C} \cdot \mathrm{h}^{-1}$ to -20 and $-30{ }^{\circ} \mathrm{C}$. Percent survival was based upon three replications of 10 buds for each cultivar per test temperature.

content averaged $12 \%$ in untreated samples, and $13 \%$ in alginate encapsulated samples without sugar imbibition. The interaction between treatments and cultivars was also significant (Table 2), because gel encapsulation was significantly better for 'Jonagold' and 'Mutsu', but not for 'K-14'. However, survival achieved by encapsulation with alginate alone was unacceptably low (23\% average). Imbibition with sugars was necessary for good survival in all cultivars.

Data from these experiments support use of sugar-alginate stabilization to increase desiccation tolerance and survival in liquid nitrogen of cold-tender apple buds. Sucrose imbibition and encapsulation have been used in tissue culture to cryopreserve shoot tips of grape (Vitis vinifera L.) (Plessis et al., 1993) and potato (Solanum tuberosum L.) (Fabre and Dereuddre, 1990). The osmotic effect of molar concentrations of sucrose can provide a dehydration gradient and a driving force to desiccate tissues during cryopreservation. Concentrated sugar solutions are also known to be good glass formers and stabilizers of labile macromolecules when aqueous solutions are subjected to cryogenic temperatures (Slade and Levine, 1990).

Conventional dormant bud cryopreservation is most successful when samples are collected at maximum cold hardiness, often about a 1 month time period in midwinter. Sugar-alginate stabilization of cold-tender apple buds significantly increased survival in liquid nitrogen for buds collected September, October, November, and January (Fig. 5, Table 3). All cultivars survived reasonably well $(60 \%$ to $74 \%)$ after sugar imbibition. Survival following cryopreservation in liquid nitrogen was significantly different among collection dates for nontreated controls, but not for the stabilization treatments. For nontreated controls, lowest survival was in September, when buds were vegetatively mature but not freeze and desiccation tolerant. While none of the control September buds survived, and only $17 \%$ of the control October

Fig. 3. Relationship between moisture content and survival following cryopreservation in liquid nitrogen $\left(-196^{\circ} \mathrm{C}\right)$ for dormant vegetative buds of 'Jonagold', 'K-14' and 'Mutsu', collected 15 Sept., Oct., and Nov. 1994 and 15 Jan. 1995. Each datum is the mean of 30 buds.

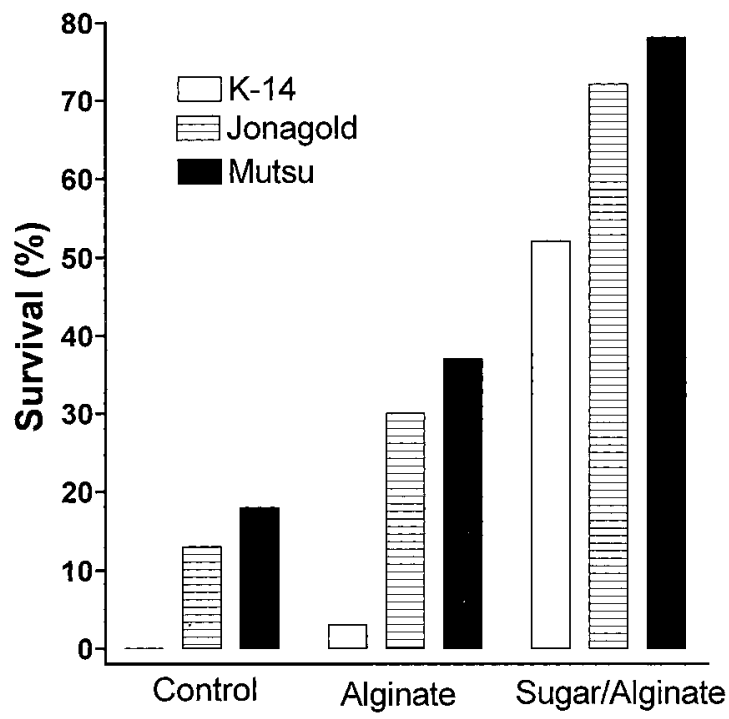

Fig. 4. Response of dormant vegetative buds of three cultivars collected 15 Jan. 1994, comparing alginate encapsulation and alginate encapsulation with sugar imbibition to nontreated control buds. Percent survival was based upon three replications of 10 buds per cryopreserved sample. 
Table 2. Analysis of variance (ANOVA) for cryopreservation survival of 'Jonagold', 'K-14' and 'Mutsu' comparing control, alginate and sugar/alginate encapsulation (full model MSE $=0.010727, \mathrm{df}=24$ ).

\begin{tabular}{lccc}
\hline \hline Source & df & F value & $P$ value \\
\hline Treatment & 2 & 21.84 & 0.0001 \\
$\quad$ Cultivar (C) & 2 & 186.26 & 0.0001 \\
$\quad$ Sugar-alginate (SA) & 4 & 18.86 & 0.0001 \\
$\quad$ C $_{\{\text {Xtimesx }}$ SA & 173.61 & 0.0001 \\
$\begin{array}{l}\text { Contrast } \\
\quad \text { Control }\end{array}$ \\
\hline
\end{tabular}

Fig. 5. Response of cold-tender apple cultivars collected from early to late stages of vegetative bud dormancy. Cryopreservation data are survival means for 'Jonagold', 'K-14', and 'Mutsu' from four replications with 10 buds per replication.

Table 3. Analysis of variance (ANOVA) for cryopreservation survival of 'Jonagold', 'K-14' and 'Mutsu' comparing early and late stages of bud dormancy (full model MSE $=0.0243, \mathrm{df}=24$ ).

\begin{tabular}{lcrc}
\hline \hline Source & df & F value & $P$ value \\
\hline Month (M) & 3 & 4.87 & 0.008 \\
Sugar-alginate (SA) & 1 & 143.75 & 0.001 \\
Cultivar (C) & 2 & 2.89 & 0.07 \\
M $_{\{\text {Ximesx\} }}$ C & 6 & 1.44 & 0.24 \\
M $_{\{\text {XimesX\} }}$ SA & 3 & 0.27 & 0.84 \\
M $_{\{\text {XimesX\} }}$ SA & 1.31 & 0.28 \\
\hline
\end{tabular}

buds survived, $60 \%$ and $70 \%$, respectively, of the sugar-alginate treated buds survived. As cold acclimation progressed with the season, bud survival of controls also increased, but none attained $60 \%$ or higher survival as did the treated samples.

Visual scoring of January 1994 samples, conducted at Fort Collins, Colo. compared to recovery following budding to rootstocks, conducted independently at Geneva, N.Y., was highly correlated for all cultivars and collection dates. Differences in survival between visual and grafting evaluation may be expected due to damage that is not evident in tissues which were not exposed for visual examination, and/or differences may be due to some degree of subjectivity from visual evaluation. However, correlation of survival between evaluation by visual scores and bud growth following grafting of cryopreserved buds $\left(R^{2}=0.93\right)$ assures that evaluation by visual ratings was highly effective.

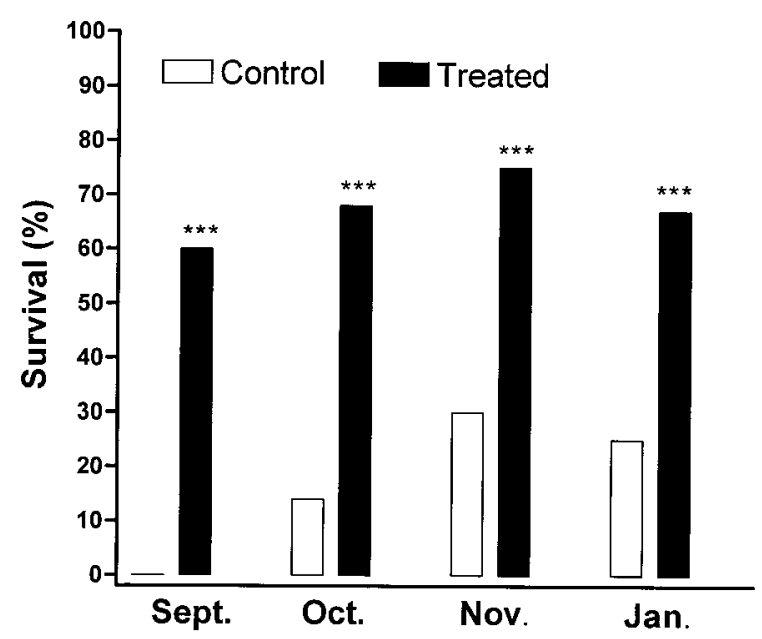

The protocol outlined herein, can be an improved method for application in preservation of apple germplasm, and other vegetative tissues. The nontoxic properties of the cryoprotectants, and the simplicity and high survival following recovery from liquid nitrogen, appear to be very desirable attributes in conservation of germplasm through cryopreservation.

Carbohyorate-Analysis: While analysis of buds themselves would have been ideal, the limited weight of tissue available in an individual bud precluded such a study in this project. Therefore, analyses of soluble carbohydrate levels in cortical tissues was studied instead. Stabilization treatments altered carbohydrate levels in the cortex of stem tissues. Four soluble sugars (glucose, fructose, sucrose, and raffinose) predominated in buds harvested in September, October, November, and January (Fig. 6).

The most striking change in twig cortical tissue carbohydrate levels was an increase in glucose and fructose. One explanation might be the action of hydrolytic enzymes in the cell wall (ap Rees, 1988). The presence of a hydrolytic enzyme, such as invertase, in cell walls could explain why sucrose remains unchanged in treated samples. After $3 \mathrm{~d}$ of imbibition, apparently all sucrose imbibed into intercellular spaces of the cortical tissues was hydrolyzed. If enzymatic hydrolysis of sucrose is occurring, it is expected that the amount of fructose and glucose should increase in approximately equal quantities, and the data support such an assumption (Fig. 6). While in nature raffinose has been shown to accumulate in a number of diverse species during cold acclimation, (Bachmann et al., 1994; Castonguay and Nadeau, 1998; Imanishi et al., 1998; Stushnoff et al., 1994) the significance, if any, of its accumulation in pre-cryopreservation stabilization treated buds in the months of October and November is unknown.

Encapsulation and treatment with sugars, stabilized dormant bud tissues from cold-tender cultivars and enhanced recovery from cryopreservation in LN. Sugar-alginate stabilization increased tolerance of dormant, cold-tender vegetative apple buds 
Glucose

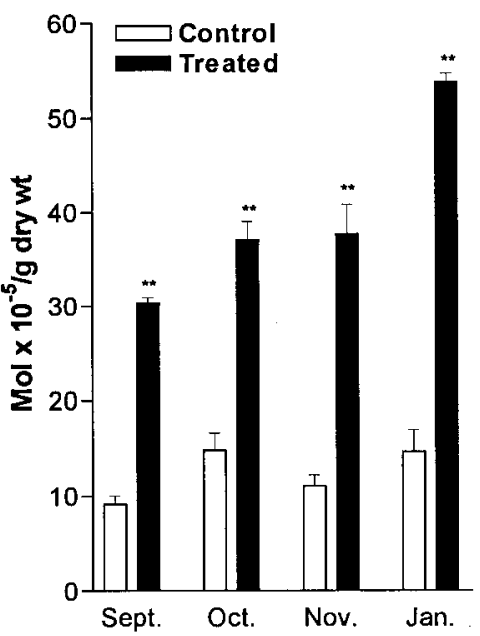

Sucrose

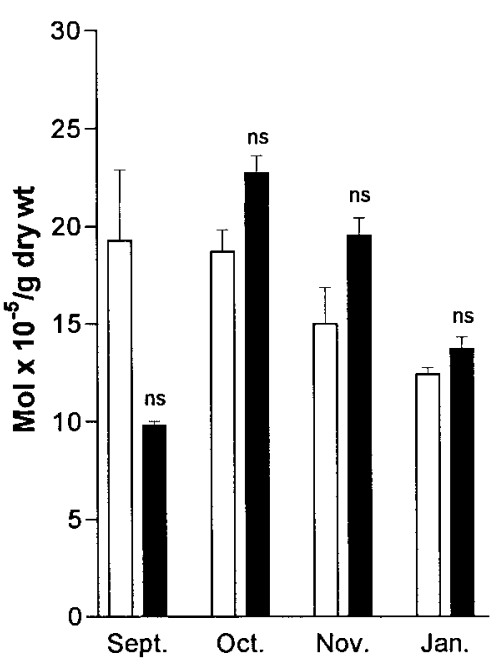

Fructose

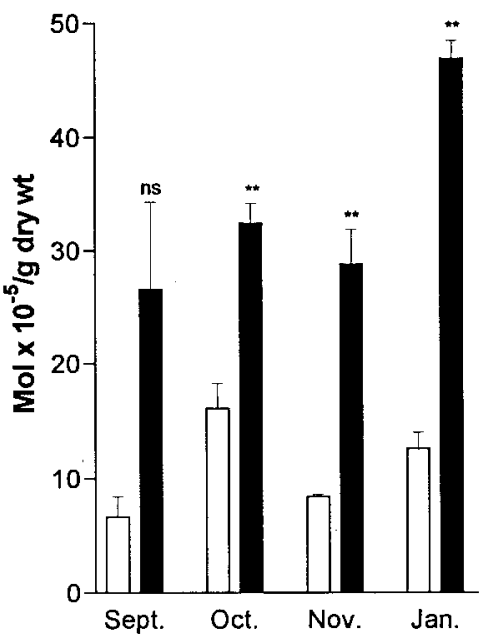

Raffinose

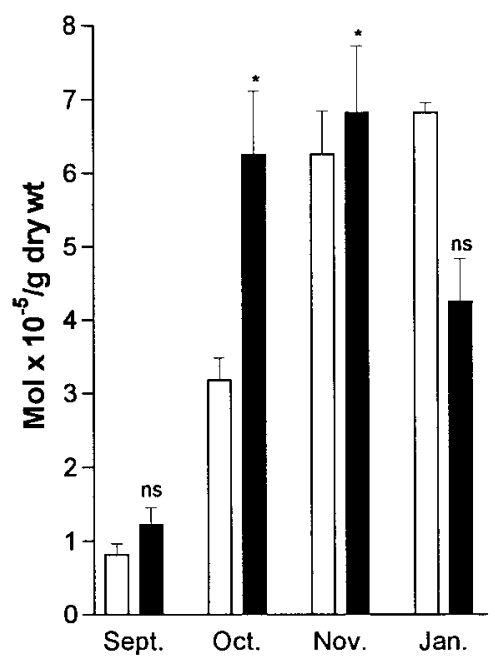

Fig. 6. Soluble sugars from cortical tissues for treated and control sample Significance determined by an unpaired Student's $t$ test for carbohydra levels comparing treated tissues with control tissues. Means were derive from three replications. Vertical bars $=$ sE.

\section{Literature Cited}

Alscher, R. and J.R. Cumming. 1990. Stress responses in pl Adaptation and acclimation mechanisms. Wiley-Liss, New York ap Rees, T. 1988. Hexose phosphate metabolism by nonphotosynt tissues of higher plants, p. 3-11. In J. Preiss (ed.). Carbohydrate P.K Stumpf and E.E. Conn (eds. in chief). The biochemistry of pl a comprehensive treatise. vol. 14. Academic Press, San Diego, C Bachmann, M., P. Matile, and K. Keller. 1994. Metabolism o raffinose family oligosaccharides in leaves of Ajuga reptans L. Physiol. 105:1335-1345.

Benson, E.E., T. Lynch, and J. Jones. 1992. The detection of peroxidation products in cryoprotected and frozen rice cells: $\mathrm{Cc}$ quences for post-thaw survival. Plant Sci. 85: 107-114.

Burke, M.J. 1987. The glassy state and survival of anhydrous bio cal systems, p. 358-364. In: A.C. Leopold (ed.). Membranes, met lism and dry organisms. Cornell Univ. Press, Ithaca, N.Y.

Carpenter, J.F., J.H. Crowe, and T. Arakawa. 1990. Comparisc solute-induced protein stabilization in aqueous solution and ir

frozen and dried states. J. Dairy Sci. 73:3627-3636.

Carpenter, J.F., S.J. Prestrelski, and T. Arakawa. 1993. Separation of freezing- and drying-induced denaturation of lyophilized proteins using stress-specific stabilization. Arch. Biochem. Biophys. 303:456464.

Castonguay, Y. and P. Nadeau. 1998. Enzymatic control of soluble carbohydrate accumulation in cold-acclimated crowns of alfalfa. Crop Sci. 38:1183-1189.

Crowe, J.H., J.F. Carpenter, L.M. Crowe, and T.J. Anchordoguy. 1990. Are freezing and dehydration similar stress vectors? A comparison of modes of interaction of stabilizing solutes with biomolecules. Cryobiology 27:219-231.

Crowe, J.H., L.M. Crowe, J.F. Carpenter, A.S. Rudolph, C.A. Wistrom, B.J. Spargo, and T.J. Anchordoguy. 1988. Interaction of sugars with membranes. Biochem. Biophys. Acta 947:367-384.

Crowe, J.H., M.A. Whittam, D. Chapman, and L.M. Crowe. 1984. Interactions of phospholipids monolayer with carbohydrates. Biochem. Biophys. Acta 769:151-159.

Fabre, J. and J. Dereuddre. 1990. Encapsulation-dehydration: A new approach to cryopreservation of Solanum shoot-tips. Cryo-Letters 11:413-426.

Forsline, P.L., L.E. Towill, J.W. Waddell, C. Stushnoff, W.F. Lamboy, and J.R. McFerson. 1998. Recovery and longevity of cryopreserved dormant apple buds. J. Amer. Soc. Hort. Sci. 123:365-370.

Guy, C.L. 1990. Cold acclimation and freezing stress tolerance: Role of protein metabolism. Annu. Rev. Plant Physiol. Plant Mol. Biol. 41:187223.

Hincha, D.K. and J.M. Smith. 1990. Proteins from frost hardy leaves protect thylakoids against mechanical free thaw damage in vitro. Planta 
Slade, L. and H. Levine. 1995. Glass transitions and water-food structure interactions, p. 103-234. In: J.E. Kinsell (ed.). Advances in food and nutrition research. vol. 38. Academic Press, San Diego, Calif.

Smirnoff, N. and Q.J. Cumbes. 1989. Hydroxyl radical activity of compatible solutes. Phytochemistry 28:1057-1060.

Steponkus, P.L. 1984. Role of the plasma membrane in freezing injury and cold acclimation. Annu. Rev. Plant Physiol. 35:543-584.

Stushnoff, C. 1991. Cryopreservation of fruit crop genetic resourcesImplications for maintenance and diversity during conservation. HortScience 26:518-522.

Stushnoff, C., R. Remmele, Jr., V. Esensee, and M. McNeill. 1994. Low temperature induced biochemical mechanisms: Implications for cold acclimation and de-acclimation, p. 647-657. In: M.B. Jackson and C.R. Black (eds.). Interacting stresses on plants in a changing climate. NATO ASI series I. Global environmental change. vol. 16. SpringerVerlag, Berlin.

Stushnoff, C., C.W. Vertucci, and L.E. Towill. 1988. Assessment of water status by differential scanning calorimetry for cryopreservation of dormant buds. Proc. N. Amer. Thermal Anal. Soc., 17th Annu. Conf.
$1: 246-251$

Sweeley, C.C., R. Bently, M. Makita, and W.W. Wells. 1963. Gas-liquid chromatography of trimethylsilyl derivatives of sugars and related substances. J Amer. Chem. Soc. 85:2497.

Tyler, N.J. and C. Stushnoff. 1988a. Dehydration of dormant apple buds at different stages of cold acclimation to induce cryopreservability in different cultivars. Can. J. Plant Sci. 68:1169-1176.

Tyler, N.J. and C. Stushnoff. 1988b. The effect of prefreezing and controlled dehydration on cryopreservation of dormant vegetative apple buds. Can. J. Plant Sci. 68:1163-1167.

Vertucci, C.W. and C. Stushnoff. 1992. The state of water in acclimation from Malus and Amelanchier and its relationship to winter hardiness. Physiol. Plant. 86:503-511. 